\title{
Course developers as students: a designer perspective of the experience of learning online
}

\author{
Iain McAlpine ${ }^{\star}$, a , Tony Koppi ${ }^{\mathrm{a}}$, Jan McLean ${ }^{\mathrm{a}} \&$ Elaine Pearson ${ }^{\mathrm{b}}$ \\ ${ }^{\mathrm{a}}$ The University of New South Wales, Sydney, Australia; ${ }^{\mathrm{b}}$ University of Teeside, \\ Middlesbrough, UK
}

Academic developers of online courses may not have experienced this mode of learning and teaching from the learner perspective. This article makes a comparison between suggestions for online course design from research literature and user perspectives from a focus group, responses to questions on the most and least effective aspects of online study and lasting impressions, and from reflective diaries kept by two of the authors while they were engaged in study from online courses. This direct evidence is used to highlight key issues in the literature from the viewpoint of the learner.

\section{Introduction}

Academics developing courses have their own experiences as students to draw upon. The experience of online learning, however, is still new to many people and many developers of online courses have no experience of learning online before trying to teach in this mode. Although developers of online courses can draw on their experiences in other modes of teaching and learning, lack of experience as an online learner makes it particularly difficult for people to design and teach in this mode. This lack of student experience means they may not know what practices to avoid and therefore they may inadvertently cause unforseen difficulties for the students.

This paper considers online learning from the perspectives of the teacher/designers, and the students, of courses that are entirely online for off-campus students. A major issue for teachers and designers is to attain a level of student engagement with the course, to keep students on track and making satisfactory progress, and to ensure that students are developing effective levels of knowledge and skill. In many instances, this means using online discussions as a substitute for on-campus tutorial

ॠCorresponding author. Educational Development \& Technology Centre, Level 4 Mathews Building, University of New South Wales, Sydney 2052, Australia. Email: i.mcalpine@unsw.edu.au 
groups, to maintain a dialogue among students and with the tutor on issues relating to course topics. These discussions present interesting challenges for both teachers and students who may be relatively inexperienced with this mode of learning and teaching.

Research literature on the constructivist approach to learning and teaching and the implications for online course design, is considered to identify some key design issues for online courses. This is considered in relation to student feedback from surveys, focus groups and reflective diaries, to gain student perspectives on online courses. These include feedback from the authors, reflecting on their own recent experiences as online students. Student perspectives are compared with recommendations from research literature to suggest some practices to avoid, and some tips for better practice, from the perspective of the online student.

\section{Online learning and teaching}

A key point identified from research is that teaching and learning online requires an approach to instructional design that embeds effective learning strategies. Current approaches to curriculum design demonstrate a move from content-centred curricula to designs that focus on learning outcomes (Oliver \& Omari, 1999). This change reflects the adoption of constructivist approaches to teaching and learning. Active learning by problem solving is a key aspect of any constructivist environment (Reeves \& Okey, 1996). Oliver and Omari (1999) suggest that effective university learning involves:

- high levels of activity and engagement;

- a motivating environment based on a well structured knowledge base;

- finding solutions to real-world problems;

- collaborative problem-solving;

- active communication among students and with the tutor.

These learning activities are seen to support higher-order thinking and learning. Courseware designed to incorporate these forms of constructivist learning activities is likely to support effective learning.

Many approaches to online courseware show a tendency to 'reformat on campus course materials and learning strategies into an online form' (Parker, cited in Oliver \& Omari, 1999, p. 2). This approach is considered to be an underutilization of the technology. Some approaches to online material for off-campus students have been identified as using a 'write/text' paradigm. This is characterized by a didactic approach in which 'learners were presented with screens of information followed by assessment activities to demonstrate recall and understanding' (Brunetto et al., 1999, p. 64). These approaches, while they achieve the important goal of enabling offcampus students to study online, do not apply the constructivist approaches developed to attain higher-order learning outcomes. 


\section{Constructivist approach}

The constructivist theoretical position has led to a range of approaches to instructional design of online courseware that exemplify specific approaches such as problem-based or case-based learning or collaborative learning. Problem or case-based approaches immerse the learner in complex tasks that reflect the type of real-world issue that the learners will have to deal with as a working professional. Online technologies are used to present the problem scenario and support the student with guidance, access to information, resources, and learning tools. Problem solving activities may be individual or group activities (e.g. Romiszowski, 1990; Oliver \& Omari, 1999; Minasian-Batmanian et al., 2000). Collaborative learning approaches develop skills in teamwork, negotiation, taking account of other perspectives, information seeking and analysis, and critical thinking. These approaches are also likely to be based around case-based scenarios, however the instructional process is specifically designed to be student focused and to develop skills in problem-solving as a group (Milter \& Stinson, 1995; McAlpine, 2000). These approaches have been specifically developed to address deficiencies in typical graduate skill profiles by fostering higher-order cognitive skills and personal communication, problem-solving and teamwork skills.

Central to aiding knowledge construction is raising the learner's awareness and understanding of the process of learning - that is to develop their metacognitive skills or ability to learn how to learn. This may involve, for instance, helping learners develop awareness of how they go about learning, their learning goals, the ability to plan and evaluate learning strategies, and to monitor progress (Jonassen et al., 1993; Reeves, 1999). This is also a crucial element in allowing students to gain control over their learning, and to become self-directed learners, which is widely accepted as a goal of student-centred learning (Brookfield, 1986; Laurillard, 2002).

\section{Learning communities}

Learning communities, or communities of practice, are considered to have evolved from the constructivist approach as a way of addressing authentic problems (Johnson, 2001). Their purpose and value are closely related to the key concepts of constructivism, including:

- open-ended problems;

- learning from real-world problems;

- having shared goals;

- using cognitive tools; and

- a tutor's role as facilitator or coach (Johnson, 2001).

In a course structured on these concepts, the process of dealing with problems in a collaborative way is considered to foster, and be aided by, a sense of community among learners. Processes that open up the learning process to facilitate participation, and to enable learners to move from peripheral to central status as quickly as possible are valuable in this context (Wegerif, 1998). The role of the tutor in facilitating this 
process by providing guidance, and the course design in providing access and support, are important contributors to creating the appropriate level of collaboration (Oliver et al., 1998).

\section{Online discussion}

Appropriate and effective use of online discussion forums is a critical part of the instructional design process for online learning, as this enables the communication and tutor facilitation processes. Discussion forums, both synchronous and asynchronous, may be the main form of communication between the tutor and the students, and among students when the students are off-campus. As the online discussions play a critical role in the teaching/learning process, the use of discussion forums needs to be planned to integrate into the overall learning process.

The vital part of using online discussion in any format is to keep the students actively engaged. Palloff and Pratt (1999) suggest a range of activities that foster active engagement, including:

- posting instructions and learning expectations;

- forming teams and posting guidelines for their performance;

- encouraging a search for real life examples;

- using dialogue as enquiry by encouraging thought provoking expansive questioning;

- sharing responsibility for facilitation among group members;

- promoting constructive feedback.

Methods for facilitating dialogue as enquiry may include using open-ended questions (e.g. 'what do you consider to be the ethics of a computing professional?' McLoughlin \& O'Sullivan, 2000, p. 47) or using statements that are designed to promote discussion (Palloff \& Pratt, 1999).

\section{The tutor's role}

The role of the online tutor is critical in attaining effective learning outcomes. Tutors need to set appropriate activities and provide the right kind of guidance. Feedback from experienced tutors indicates that online tutoring can be more demanding than tutoring in a face-to-face situation. Some students show a high level of appreciation for online conferences, but students are likely to be dissatisfied if there is a lack of participation by others (Mason $\&$ Weller, 2000). For online discussion to be successful the topics must be clearly related and relevant to the learning situation, and the online discussion needs to be an integral part of the learning process. Students need to be motivated through appropriate activities (Salmon, 2002) and participation should be directly assessed or associated with assessment tasks. Those who are not active in the course should be contacted and monitored by the tutor. Without that support, even the most experienced learner can fall behind and out of a course (Roffett, 2000). 


\section{Guidance and scaffolding}

Traditional approaches to instructional design emphasize the importance of student and instructor guides as components of a learning package (e.g. Dick \& Carey, 1985). Online courses may not use this design element, which can lead to problems for students using online courseware. In an evaluation of a range of online courseware, Brunetto et al. (1999) identify learning supports, or scaffolding, as an essential element of online learning (with learning activities and content). They also found that scaffolding was not a common design aspect in many of the online courses and that the means of doing this varied widely due to the lack of standard approaches to design for online courses. They suggest several approaches to this, including:

- learners can be encouraged to scaffold learners;

- teachers/trainers/facilitators can act to scaffold learners;

- learning systems can be designed to track learners' progress and to provide intelligent tutoring to guide further activity based on previous learning success;

- electronic support systems can be created with the capacity to provide assistance at the point of need (Brunetto et al., 1999, p. 67).

Scaffolding can be considered as guidance and support needed at the beginning of a course or activity that can be withdrawn or ignored once the student is competent to manage the activity. Hannafin et al. (1999, p.131) describe a range of guidance or scaffolding approaches that may be necessary in courseware to assist the learner towards the most effective learning. These are:

Procedural Guides the learner in using the technology in order to engage in the learning activities.

Conceptual Guides learner in what to consider; considerations when problem task is defined.

Metacognitive Guides how to think during learning: ways to think about a problem under study and/or possible strategies to consider; initial role in finding and framing problems, and ongoing role during resolution.

Strategic Guides in analysing and approaching learning tasks or problem; provided initially as macrostrategy or ongoing as needs or requests arise.

Student guidance, focusing on these aspects, may be incorporated into the course in different ways. Procedural guides would focus on finding a way around the course materials and how to do some of the basic organizational aspects. Other guides might relate to study skills, such as managing the learning process and working with other students on group tasks. These guidelines may be embedded in the courseware or actions by the tutor, or both. 


\section{Review of courseware design issues}

The constructivist approach, with its emphasis on open-ended problem solving and collaboration, is considered by many to be the most effective design model for an online course. This approach is based on models for learning and teaching that have been developed to achieve high-level learning outcomes. Critical factors for online course design are to create learning activities based on constructivist principles, and to design online processes that enable these learning activities even though the students are off-campus. Online discussions play a key role in enabling group problem-solving, the formation of a learning community, the facilitation of knowledge construction by the tutor and provision of guidance in the most effective approaches to the learning task. Online course design also involves the provision of access to relevant information, and to an appropriate level of guidance, through the tutor and other means such as guides to process and technical support, to enable the student to focus on the learning task and to carry it out effectively.

The following section of the paper describes the authors' approach to gathering feedback from student experiences of online study, taking account of the desirable online course features considered above.

\section{Method}

The aim of the project was to gather data that reflected the experiences of the authors and close colleagues in relation to being a student on a course conducted entirely online, and to consider how these data reflected on approaches to online course design. Awareness of the desirable attributes of an online course, outlined above, was an important consideration in the study. By taking account of the student perspective, an examination of the implementation of course design could be conducted. This reflects some of the outcomes of the design approach, and leads to some suggestions for providing effective support to students in the design and implementation of online courses.

\section{Research questions}

The following questions were used as a focus for this study:

- What elements of the design of online learning courses contribute to effective outcomes?

- What can the experience of online learning contribute to the improvement of online course design?

\section{Data gathering}

The following data sources were drawn upon:

- Reflective diaries kept by two of the authors while they were students in an online course on the topic of online learning, studied in 2001. 
- A survey that included some authors and close associates who were also developers. The survey had three open-ended questions, asking about positive experiences of online study, negative experiences, and lasting impressions. Surveys were sent to five people and four were completed.

- A focus group, conducted by one of the authors, with a group of students who were experienced in online learning. This group had completed a year of part time study for an online masters program. One of the authors was involved in the design of the course, and was known to the students. Twelve students participated in the focus group at the end of the 2000 academic year.

The method of analysis was to group the responses thematically, so that a range of comparative and contrasting perspectives were available on the key issues. Data from all sources have been aggregated to enable a thematic grouping, using the actual words from the data sources as much as possible, to reflect the student experiential perspective (Seidman, 1991).

\section{Results}

Student comments from the focus group and the diaries reflect the major issues for course design outlined in the literature review:

- course design around open-ended, real-world problems;

- group problem-solving;

- developing a learning community;

- the tutor's role as a facilitator; and

- course design for guidance and student support.

The student perspective on each of these is considered below, with the addition of some lasting impressions of the overall experience of online learning taken from the diaries and the survey. As the inclusion of all responses would take up too much space, a selection indicating the overall directions of the comments is included. For each comment the source, the reflective diaries, the survey, or the focus group, is indicated in brackets.

\section{Course design around open-ended, real-world problems}

While this is an important issue, it did not elicit a wide range of student comments. It is likely that the students commented mainly on the experience of dealing with the problems, which is covered under the next topic of group problem-solving, rather than the nature of the problem tasks. Some comments on the nature of the learning tasks are:

Courses I enjoyed the most were those that included regular amounts of small assessment or regular activities, this ensured that I logged into the course regularly. This may not be a fault of the course but does help keep students involved with the online course. (Survey) 
the assignments ... were interesting and motivating — due to being 'real life' authentic tasks, with real contexts. (Survey)

the tasks all promoted learning and I felt I learned a lot both pedagogically and technically. (Survey)

Have just completed the first assignment which was a well-drafted, authentic task-quite enjoyed it and feel at least I have done something! (Reflective Diary)

It appears that the use of real-world problems as a focus of the learning activities was valued. Additional perspectives on the nature of the experience are given in the next section.

\section{Group problem-solving}

The process of learning from group tasks drew a wide range of comments. This issue, more than any other, seemed to attract the students' attention. Opinions were polarized, with the students tending to either like it or hate it, depending upon the experience. A student from the focus group, who had completed several subjects online said:

Yes it was good-nothing will ever replace sitting in a room with people and talking to them but to do the group work ... (online)-you certainly got to know the group members much better and you interacted with their thoughts and ideas and that's the way you learned.

Some comments indicate positive experiences:

I teamed up with a chap from New Zealand and I found that enjoyable as we worked well together. It was good to have that level of collaboration and I was pleased with the assignment tasks we did. (Survey)

Once we worked out who could do things during the week and who could do things on weekends then everyone was comfortable with that you could then share the work so that it was easy and it worked well once you worked that out - but working out the logistics often took the time- once the logistics were worked out then it flowed pretty well. (Focus Group)

Collaboration was useful for accomplishing a task-discussions were actually carried out by three one-hour telephone conferences (Focus Group)

We tended to find though that a couple of telephone calls we'd organize it quicker than with the chat systems - our group got particularly well organized for that particular session ... it then proceeded to run extremely well in pushing our assignments forward. (Focus Group)

One respondent commenced a course using a collaborative approach and was asked, during the course, to change to individual work. The reflective diary response was:

I think the course has lost a lot because of the loss of collaboration. It actually took an extra effort to work like that but the learning should have been better. It is now easier just to do my own thing and not worry about any body else or have to incorporate anyone else's points of view. 
The respondent's solution was to substitute work colleagues for fellow students:

I actually talk about the topic tasks with people here at work and receive comments and suggestions from them prior to and whilst doing the task. I find it very useful to consult with my colleagues to help consolidate and formulate my ideas. It's good reflection stuff. I am using my work colleagues in lieu of my classmates to discuss the coursework.

In general, the responses relating to collaborative work were positive. One student, however, points out some associated stresses:

It's quite positive the experience but you can overdo the group stuff too because I found the group stuff quite time consuming so whilst I agree that yes it's valuable and yes we did work out how to do it more effectively as we went along, having to do group stuff so often with so many units in a year when a lot of us travel away from our places of work, etc., etc., my judgement is 'yes if you ask me I'd say continue with it but let's not do it at every opportunity-let's be strategic about when you choose for us to do group work ... (Focus Group)

Collaborative tasks can cause major problems if students are not motivated to work together, as these responses indicate:

The collaborative task isn't going well. The person has disappeared. He sent me an email yesterday (four days after my initial one) which shows he isn't clear about the task and clearly hasn't started any work on it. I really need to get on with it as I can't extend my deadline ... so I feel a real sense of urgency. I don't think this is a great task to collaborate on. I find collaborating with someone I don't know really uncomfortable. Mason and Weller (2000) suggest I do Task 2 alone given the problems with collaborating... (Reflective diary)

There's a major problem with group work if you can't get the cooperation of one person ... (Focus Group)

The courses that are the focus of these comments clearly made use of group tasks as an important part of the course design. When this process works well, students appear to find it rewarding, leading to the intended outcome of learning to work as a team, sharing ideas among the group, and a deeper understanding of the topic. This outcome certainly isn't guaranteed however, as collaboration can go awry very easily if some members of a group do not contribute effectively to the process. Group processes may also place additional stress on the group members, and could be overdone in some situations.

\section{Developing a learning community}

While some students appeared to enjoy the process of group work online more than others, the sense of being a part of a learning community did not figure in the comments. If the group process worked that was fine, but the community aspect or sense of belonging to a group only elicited comments when its absence was particularly felt, as is seen by the following:

I would have preferred 'traditional' face -to-face interaction. I found the lack of being part of a 'real' learning community frustrating and the on-line set up didn't compensate. (Survey) 
... the feelings of isolation and not really feeling part of a class-I never got to know anyone other that the tutor (whom I got to know very well) - while we were invited to contribute to discussion forums etc, I felt we needed more structure to 'force' us to engage with each other. (Survey)

To work in a team when you don't know what people look like is a bit strange to start with. (Focus Group)

... still no attempt to 'pull together a class'-I have no feeling whatsoever of actually studying a subject. (Reflective Diary)

Students who experienced success with group processes may have felt a sense of a learning community, evidenced by their satisfaction in working together. This could be considered to be a part of the group learning process rather than a separate issue. It has been considered separately in this study because of some literature that focuses on this issue directly, and also because of the strength of the students' comments. This issue may also overlap with the next sections on the role of the tutor and the course design, as these may influence the perception of belonging to a learning community.

\section{The tutor's role as a facilitator}

The role of the tutor in an online course may be critical to the degree of success. As students are both isolated and probably coping with a new approach to learning and new technology, they naturally look to the tutor to provide a positive input. It appears that if this doesn't happen, perhaps because the tutor holds the belief that the students will work things out for themselves, then the students may experience some concerns. Some comments reflect this:

... there was never any real 'start' to the course where we all had to do something together and therefore to find out who else was studying. (Survey)

the person running the course did not make much of an effective contribution. (Survey)

My worst experience was my first online course, the lecturer was very absent from the course, email did not get answered for a considerable period of time, the bulletin board was empty and many students complained about a feeling of being lost in the course. (Survey)

The tutor's role, however, can be seen to be very effective:

... the level of tutor support, feedback and responsiveness (and flexibility) ... was extremely high. (Survey)

Very much appreciated [the tutor's] response (via email). A positive aspect of the work so far is (the tutor's) openness to feedback and responsiveness to issues raised. I've realized that one advantage of online learning is that the teacher can respond rapidly to issues/ concerns and let everyone know outcomes immediately. (Reflective diary)

The critical issue for the tutor appears to be the degree of involvement in the online discussions. Moderating these discussions can be seen as a new skill, about which a body of research is emerging that is leading to a range of guidelines such as those in Salmon (2000, 2002). 


\section{Course design for guidance and student support}

Respondents were strongly negative about situations in which there did not appear to be an appropriate level of guidance, or 'scaffolding'. When the way to use the online materials was not clear, this led to high levels of frustration and confusion:

There is no place to go to 'get started' which tells us how we are going to work together, what we will do, etc. (Reflective Diary)

Interface design-irrelevant metaphors; distributed information on any one topic, especially assessment; spurious labelling, e.g. weekly tasks under either 'computer laboratory' or 'lecture theatre'. (Reflective Diary)

What does a discussion forum need to be student centred? It needs to be easily accessible, easy to read messages in a threaded format, easy to post replies to any particular author, and easy to post a new question (i.e. start a new thread). Several of these student centred attributes are missing from the current forum. (Reflective diary)

The final assessment was poorly 'scaffolded' for students ... i.e. no preparation ... and seemed to be on a different topic to the course. (Survey)

It came as a big shock in about week 5 to discover a large assessment task worth $30 \%$ of the course was due imminently. I was working on the assumption that the submissions of the 2 weekly tasks ... was the assessment for the course. I now understand that these tasks (many of which involve considerable time and effort) are only worth $30 \%$ of the course. This is disproportionate to the effort required ... I should have been more strategic: work out where the big value tasks are and work on those. (Reflective Diary)

The data do not contain balancing comments of a positive nature about course design, scaffolding and guidance issues. Perhaps it can be considered that if the students are satisfied then the course design is good as it does not confront the student with any problems so they can concentrate upon the learning tasks. When the design leaves students confused or with a sense of no direction, as the above comments seem to indicate, then there appear to be shortcomings that need to be addressed. The above comments are mostly from reflective diaries, indicating a sense of frustration emerging from course design that did not seem to provide a clear path for the students to follow.

\section{Lasting impressions}

What was the verdict at the end of the course? Some students were left with a bad impression of online study, because a particular course was poorly managed or didn't work for them:

Remains nearly 6 months later overwhelmingly negative. Both of the course, the 'flexible delivery' mode and the school involved. (Survey)

For one respondent, the lasting impression is:

What I learned from the tasks and also that scaffolding is very important in the implementation of an online course. Its importance is paramount. (Survey) 
Fortunately, despite the inevitable problems or hurdles, most of the respondents had positive comments about the overall experience of studying online. An example of lasting impressions tells a more favourable story:

Overall I've enjoyed studying online, I have now completed five masters level papers online over the past three years. Not surprisingly, online courses are greatly effected by the abilities of the teaching staff running the course, perhaps even more so than face-toface classes.

Flexibility! Since starting my online Masters course I have shifted countries, if I had started a traditional Masters program it would have been much more difficult to continue studying. I was also able to continue with my studying while travelling.

The other thing I enjoy about online courses are lecturers who are responsive, I've experience some very good online lecturers who have been very responsive but have also let students time to interact with each other and discuss issues. Feedback from the online teacher was perhaps the biggest factor effecting my reaction to the course, as well as the amount of interaction happening in the bulletin board. (Survey)

\section{Discussion}

The project reported here, set out to answer the following questions:

- What elements of the design of online learning courses contribute to effective outcomes?

- What can the experience of online learning contribute to the improvement of online course design?

In considering the extent to which these questions have been answered, the discussion will focus on the five themes of:

- Course design around open-ended, real-world problems.

- Group problem-solving.

- Developing a learning community.

- The tutor's role as a facilitator.

- Course design for guidance and student support.

\section{Course design around open-ended, real-world problems}

The first key course design element is a constructivist approach of using problem or case based, real-world scenarios as a focus for the learning process (Oliver \& Omari, 1999). This approach was used to some extent by most of the online courses included in the data gathering process. Several courses made group problem-solving a central part of the course design. While the nature of the task did not elicit many comments (unlike the actual group process) the nature of the comments indicated that the students appreciated the authentic tasks. 


\section{Group problem-solving}

The next key design element is that learning from problem or case based scenarios should be a group process (Oliver \& Omari, 1999; McAlpine, 2000; MinasianBatmanian et al., 2000). This aspect of design elicited mostly positive comments, although there were situations in which the group process didn't work, which led to high levels of frustration. One important factor evident from the focus group is that it takes time to develop the necessary capability to work as a group online. The students had completed several courses online and knew most of the other participants well, and had learned to work this way. The respondents who experienced frustration were new to the experience of online group work, and often found that the people they were supposed to work with were not active in the process. Comments indicate that the respondents regretted losing the opportunity to collaborate online. It appears that some students had enrolled in the course but failed to participate in an effective way, despite this being a course requirement. This suggests that additional management processes may be required to kickstart the group process. Salmon (2000) suggests a range of activities, including easy introductory activities, to involve the students in tasks that are easily manageable before asking them to engage in a group task online, which is complex and demanding. The students in the focus group were brought together for an intensive week's study before starting the online courses, so they would know each other and clearly understand the importance of online group work. It is likely that tutor follow-up is needed if individuals do not contribute effectively.

\section{Developing a learning community}

The third key design element is the development of learning community. It is suggested that a learning community or community of practice is critical in dealing with complex open-ended tasks using a constructivist approach (Johnson, 2001). The respondents do not use language that would indicate they experienced a sense of community; however, negative comments made it clear that some students were looking for this and didn't find it. One comment made clear that the provision of a discussion forum did not mean that people would use it, and using the discussion should be a requirement of the course. The student feedback indicates specific needs, to have a sense of belonging to a group, that were not met. This raises questions about how this can be done. Clearly the use of the online discussion should be a requirement for course participants, possibly as an assessed activity. An optional activity may not engage most of the students, who will naturally focus on what they are required to do. The answers to this issue may overlap with the previous aspect of group work and the following aspect related to the tutor's role.

\section{The tutor's role as a facilitator}

The role of the online tutor is the next key design element. Palloff and Pratt (1999) suggest a range of proactive tutor activities including posting instructions and expectations and using dialogue as a process of inquiry. A broader range of tutor activities 
is provided by Salmon (2000). Feedback on this issue is clear cut. Some comments indicate that the tutor was largely absent from the online course and so no activities were undertaken that would facilitate engagement by the students. These comments indicate considerable frustration at the lack of tutor involvement. By contrast other comments indicate strong appreciation of the tutor's willingness to respond and provide support. This suggests that tutors need to learn appropriate techniques for moderating online discussions.

\section{Course design for guidance and student support}

The final design element, course design for guidance and student support, seemed to create many issues for the students. This is a critical element that is a mix of the way the online courseware is designed to provide navigation, the presence of appropriate student guides within the coursework, and the way that the course is managed by the tutor. Brunetto et al. (1999) suggest that this element is not well done in many online courses. Hannafin et al. (1999) propose several aspects of guidance or scaffolding required. These include procedural, conceptual, metacognitive and strategic aspects relating to the learning tasks, for which different forms of guidance may be needed. Student feedback indicates some dissatisfaction with this aspect of course design. Most of the issues seem to revolve around procedural matters rather than the conceptual material. This referred to difficulties in navigating the coursework and knowing what the assessment tasks were and where they were to be found. Confusion through lack of guidance or difficult navigation caused apparent frustration that may have influenced the student's attitude to the course overall. This may involve a careful consideration of basic aspects of online courseware design to avoid these problems.

These design elements all appear to be important elements that contribute to an effective online course. The student perspective highlights the major issues for developers to focus on, to ensure that the course is effective.

\section{Conclusions}

In this study the student perspective on course design has been used to illuminate some of the strengths and weaknesses of learning and teaching online. The constructive approach to course delivery was used as a tool to interpret and analyse the student experience and perspective. This approach has revealed that for the range of online courses included in this project, the most notable weaknesses were support for group processes, building a learning community, and courseware design to facilitate student access to all relevant components and information. These can be seen as issues relating to a fundamental aspect of course design, how learning and teaching is going to work for the learner, and secondly to aspects of scaffolding and student support to reinforce the learning and teaching process. The five key design elements all seem to be critical to the development and implementation of an online course that will foster high-level learning outcomes. 
Furthermore, by enrolling in online courses as students, course designers have gained a useful insight into where the emphasis needs to be placed to improve the effectiveness of online courses.

\section{References}

Brookfield, S. (1986) Understanding and facilitating adult Learning (San Francisco, CA, JosseyBass).

Brunetto, Y., Wharton, R. F., Oliver, R., Skippington, P. \& Towers, S. (1999) Toolboxes for online learning: evaluation report of the ANTA toolbox initiative (Brisbane, Australian National Training Authority). Available online at: http://www.anta.gov.au/toolbox (accessed July 2000).

Dick, W. \& Carey, L. (1985) The systematic design of instruction (2nd edn) (London, Scott Foresman).

Hannafin, M. J., Land, S. \& Oliver, K. (1999) Open learning environments: foundations, methods, and models, in: C. M. Reigeluth (Ed.) Instructional-design theories and models, Vol. II (Mahwah, NJ, Lawrence Erlbaum), 115-140.

Johnson, C. M. (2001) A survey of current practice in online communities of practice, The Internet and Higher Education, 4, 45-60.

Jonassen, D., Mayes, T. \& McAleese, R. (1993) A manifesto for a constructivist approach to uses of technology in higher education, in: T. M. Duffy, J. Lowyck \& D. H. Jonassen (Eds) Designing environments for constructive learning (Berlin, Springer-Verlag), 231-247.

Laurillard, D. M. (2002) Rethinking university teaching: a conversational framework for the effective use of learning technologies (2nd edn) (London, RoutledgeFalmer).

Mason, R. \& Weller, M. (2000) Factors affecting students' satisfaction on a web course, Australian fournal of Educational Technology, 16(2), 173-200.

McAlpine, I. (2000) Collaborative learning online, Distance Education, 21(1), 66-80.

McLoughlin, C. \& O'Sullivan, M. (2000) Educating software engineers for the 21 st century: assisting students to develop communication and team skills for success in the IT profession using the WWW, Open Learning 2000: Proceedings of the 4th International Conference on Open Learning, Brisbane, December 6-8 (Brisbane, Learning Network Queensland).

Milter, R. G. \& Stinson, J. E. (1995) Using Lotus Notes to facilitate action learning, paper presented at the Sixth Annual Business/Economics Teaching Conference, Chicago IL, 10 November. Available online at: http://mbawb.cob.ohiou.edu/paper1.html (accessed 19 August 1998).

Minasian-Batmanian, L. C., Koppi, A. J. \& Pearson, E. J. (2000) Developing lifelong learners: a novel online problem-based ultrasonography subject, in: D. Squires \& G. Conole \& G. Jacobs (Eds) The changing face of learning technology (Cardiff, University of Wales Press), 137-148.

Oliver, R. \& Omari, A. (1999) Using online technologies to support problem based learning: learners' responses and perceptions, AfET, 15(1), 58-79. Available online at: http://www.ascilite.org.au/ajet/ajet15/oliver.html (accessed April 2003).

Oliver, R., Omari, A. \& Herrington, J. (1998) Exploring student interactions in collaborative world wide web computer-based learning environments, fournal of Educational Multimedia and Hypermedia, 7(2/3), 263-287.

Palloff, R. M. \& Pratt, K. (1999) Building learning communities in cyberspace: effective strategies for the online classroom (San Francisco, CA, Jossey-Bass).

Reeves, T. C. (1999) Teaching and learning online: opportunities and responsibilities. Keynote address to $N E T^{\star}$ Working ' 99 Conference, Melbourne, 2 September. Available online at: http:// www.nw99.net.au/papers/reeves.html (accessed May 2001).

Reeves, T. C. \& Okey, J. R. (1996) Alternative assessment for constructivist learning environments, in: B. G. Wilson (Ed.) Constructivist learning environments: case studies in instructional design (Englewood Cliffs, NJ, Educational Technology Publications), 191-202. 
Roffett, A. (2000) Confessions of an e-dropout, IT Forum Paper \#51. Originally in Training Magazine, August 2000. Available online at: http://www.trainingmag.com.

Romiszowski, A. J. (1990) The case study methodology: interactive media and instructional design, in: H. E. Klein (Ed.) Problem solving with cases and simulations (World Association for Case Method Research and Application (WACRA), Waltham, MA, Bentley College Press).

Salmon, G. (2000) E-moderating: the key to teaching and learning online (London, Kogan Page).

Salmon, G. (2002) E-tivities: the key to active learning (London, Kogan Page).

Seidman, I. E. (1991) Interviewing as qualitative research (New York, Teachers College Press, Columbia University).

Wegerif, R. (1998) The social dimension of asynchronous learning networks, fournal of Asynchronous Learning Networks, 2(1), 34-49. 